еборейный кератоз: современные представления о патогенезе

\author{
А.К. Александрова, В.А. Смольянникова
}

ГБОУ ВПО «Первый Московский государственный медицинский университет им. И. М. Сеченова» Минздрава России

119991, Москва, ул. Малая Трубецкая, д. 8, стр. 1

Рассматриваются вопросы себорейного кератоза. Обсуждаются современные взгляды на этиологию и патогенез заболевания, особое внимание уделено гистологическим и иммунногистохимическим особенностям разных фоорм, разнообразию клинических проявлений. Описан синдром Лезера — Трела, показана возможность малигнизации себорейных кератом, их ассоциация со злокачественными новообразованиями кожи.

Ключевые слова: себорейный кератоз, иммунногистохимия, эндотелин-1, онкогены р16, р53, р63, инсулин, синдром Лезера - Трела.

Контактная инсформация: veter278@rambler.ru. Вестник дерматологии и венерологии 2014; (4): 28—34.

\title{
Seborrheic keratosis: current concepts of pathogenesis
}

\author{
A.K. Aleksandrova, V.A. Smolyannikova
}

I.M. Sechenov First Moscow State Medical University

Trubetskaya str., 8, bldg 2, Moscow, 119991, Russia

The article covers problems of seborrheic keratosis. The authors discuss current concepts of the etiology and pathogenesis of the disease paying special attention to the histology and immunohistochemistry of different forms and diverse clinical presentations. They describe Leser — Trelat syndrome as well as potential neoplastic transformation of seborrheic keratomas and their association with malignant skin neoplasms.

Key words: seborrheic keratosis, immunohistochemistry, endothelin-1, p16, p53, p63 oncogenes, insulin, Leser Trelat syndrome.

Corresponding author: veter278@rambler.ru. Vestnik Dermatologii i Venerologii 2014; 4: 28_34. 
Себорейный кератоз (keratoma senile, старческая, бородавка) (CK) - наиболее распространенная доброкачественная эпителиальная опухоль кожи, существующая во множестве клинических вариантов [1, 2]. Себорейные кератомы могут располагаться на любом участке кожного покрова, кроме ладоней и подошв, описаны случаи их возникновения на слизистых оболочках половых органов и на конъюнктиве [3-6]. Болеют лица среднего и пожилого возраста, после 50 лет распространенность достигает до 80-100\% в популяции [7]. У афро-американцев себорейный кератоз лица носит название папулезного черного дерматоза и встречается в $30-35 \%$ случаев. Проявляется заболевание на ранней стадии пятнами желто-коричневой окраски, которые постепенно темнеют и превращаются в выпуклые бляшки, как будто приклеенные к коже, чаще с папилломатозной, с сальным блеском, поверхностью. Диаметр образований может варьировать от нескольких мм до нескольких см. Очаги четко очерчены, могут быть солитарными, но чаще множественные, имеют овальную форму и располагаются по ходу кожных линий $[3,8]$. Кератомы растут медленно, годами, самопроизвольно не исчезают, детали контроля их клеточного цикла не изучены. Отечественные авторы выделяют гиперкератотический, акантотический, аденоидный и смешанный гистологические типы опухоли [9]. В зарубежной практике описывают 6 гистологических типов: акантотический, аденоидный, или ретикулярный, гиперкератотический, или папилломатозный, клональный, воспаленный и раздраженный [10]. Кроме того, в последнее время описаны 2 редких гистологических типа себорейного кератоза - с накоплением большого количества муцина в клетках (адамантиноидный) и вариант, при котором базалоидные кератиноциты выстраиваются по типу псевдорозеток [11]. При всех гистологических типах присутствуют в разной степени выраженности гиперкератоз, акантоз, папилломатоз и патогномоничный симптом - роговые и псевдороговые кисты. Интенсивность меланиновой пигментации варьирует от почти полного отсутствия до сильной степени [2, 9, 12].

Современные представления об этиологии и патогенезе заболевания противоречивы, большинство теорий не объясняют сущность патологического процесса и многообразия фрорм СK.

K фракторам, способствующим развитию СК, относят длительную инсоляцию, генетическую предрасположенность, вирус папилломы человека (ВПЧ) и иммунологические нарушения [13-17].

Вопрос о возможной малигнизации себорейных кератом остается спорным, в литературе описано много случаев, когда злокачественные опухоли кожи клинически имитировали себорейный кератоз [18-22]. Так, в исследованиях Ю.В. Лебедевой [16] расхождения клинического и патогистологического диагнозов были выявлены в 75,1\% случаев. Кроме того, по мнению автора, множественные себорейные кератомы на коже шеи и лица могут рассматриваться как фракультативный маркер висцерального рака. Известно, что гистологическая картина клональной формы себорейного кератоза сходна с таковой при псевдоэпителиоматозной гиперплазии и при плоскоклеточном раке [9]. В работе Y. Vun c соавт. [23] при ретроспективном анализе 813 гистологических препаратов с диагнозом себорейного кератоза была найдена злокачественная трансформация себорейных кератом в интраэпидермальную карциному в 4,4\%, в то время как по данным P. Rajabi с соавт. [24] в 1,4\% наблюдалась трансформация акантотической формы себорейного кератоза в бовеноидную фрорму интраэпидермального рака. Кроме того, имеются многочисленные сообщения и о коллизионных опухолях, содержащих злокачественные новообразования и CK. Так, I. Thomas [25] описал пациента с клиническим диагнозом себорейного кератоза, при гистологическом исследовании у которого была выявлена меланома в пределах себорейной кератомы. T. Terada с соавт. [26] обнаружили плоскоклеточную карциному в пределах CK у 84-летней женщины. Гистологически опухоль была представлена базалоидными клетками, с псевдороговыми кистами, с накоплениями меланина. Атипичный пул клеток наблюдался только в центре очага и был представлен клетками с явлениями ядерной атипии, митоза, апоптоза. Однако не все авторы считают возможным малигнизацию СК. M. Ishida c coавт. [27] наблюдали у больного 89 лет развитие (рост) базально-клеточного рака кожи в пределах себорейного кератоза. У данного больного при проведении иммуногистохимического исследования выявлялась экспрессия цитокератинов 17, 19 и онкопротеина р53 в опухолевых клетках базально-клеточной карциномы. В то же время при себорейном кератозе экспрессия данных маркеров не отмечалась, что позволило автору рассматривать патогенез данных образований как различный. Ассоциация СК со злокачественными немеланоцитарными опухолями кожи встречается в 5,3-9\% случаев, особенно при локализации на коже головы или шеи [23, 28]. Наиболее часто втречающимися опухолями являются интраэпидермальная и базально-клеточная карцинома. Также имеются данные о возможности малигнизации себорейных кератом. В подтверждение возможности малигнизации С. Hafner с соавт. [29] обнаружили мутации онкогена РІКЗСА (16\% кератом содержали типичные онкоассоциированные мутации E542K, E545K, H1047R) и значительное повышение экспрессии онкопротеина bcl-2 при CK, играющих важную роль в развитии злокачественных опухолей кожи и мало изученных при доброкачественных новообразованиях. Повышенная экспрессия bcl-2 регистрировалась также в исследованиях C.J. Ко, Ю.В. Лебедевой, N. Puizina-Ivie $[16,30,54]$, что было расценено как основной механизм, тормозящий апоптоз клеток при СК. Обращает на себя внимание работа, в которой D. Wrone и соавт. [31] вы- 
явили повышенную экспрессию онокобелка р63 (экспрессирующийся при плоскоклеточном раке) в базальном слое эпидермиса при СК по сравнению со здоровой кожей. Другой фрормой себорейного кератоза является синдром Лезера - Трела, при котором внезапно появляются множественные себорейные кератомы на туловище, что строго ассоциируется со злокачественными опухолями внутренних органов. К фракторам, вызывающим внезапное появление множества себорейных кератом при синдроме Лезера - Трела, предположительно относят выработку клетками злокачественных опухолей внутренних органов цитокинов - эндогенных медиаторов (трансорормирующего фрактора роста, эпидермального фактора роста и др.), влияющих на пролиферацию кератиноцитов и вызывающих быстрый рост элементов [32]. Еще в 1987 году D.L. Ellis [33] указал на роль факторов роста в развитии паранеопластических кожных синдромов. Наблюдая пациента со множественными СК, черным акантозом (acanthosis nigricans) и папилломатозом, он обнаружил выраженную экспрессию рецепторов эпидермального фактора роста (EGF-R) во всех слоях эпидермиса, за исключением рогового. Известно, что в норме EGF-R представлены только в базальных кератиноцитах, и их содержание медленно снижается по мере дифференцировки клеток. Схожие результаты были получены G. Ponti c соавт. [34] у пациента с аденокарциномой желудка и синдромом Лезера - Трела. Таким образом, предполагается тесная взаимосвязь между клиническими проявлениями СК, особенностями экспрессии EGF-R и наличием онкологической патологии внутренних органов. Большую часть злокачественных опухолей, описанных при синдроме Лезера - Трела, составляют аденокарциномы, 47,7\% из них поражают желудочно-кишечный тракт. Вторыми по частоте являются лимфопролиферативные заболевания (лимфомы, лейкемии), встречаются также единичные сообщения о высыпаниях при опухолях легких и почек [1, 50, 52]. Однако A. Saraiya с соавт. [35] описали единичный случай, когда появление множественных кератом при отсутствии онкопатологии было ассоциировано у пациентов с инсулинорезистентностью, сахарным диабетом 2-го типа, и основная роль в стимуляции синтеза ДНК и клеточной пролиферации была отведена высокой концентрации инсулина. Важно отметить, что гиперинсулинемия и наличие мутаций гена, кодирующего синтез рецептора фрактора роста фрибробластов (FGFR), характерны и для черного акантоза, который встречается в ассоциации как с синдромом Лезера Трела, так и с солитарными себорейными кератомами. Поэтому M. Blomberg с соавт. [36] рекомендуют при обнаружении мутаций гена, кодирующего FGFR, и сопутствующей кожной патологии в виде черного акантоза и/или множественных себорейных кератом проводить исследования по содержанию уровня инсулина с целью обнаружения гиперинсулинемии. Из-за чрезвычайной распространенности, доброкачественного характера се- борейного кератоза и его развития в возрастной группе с высоким риском появления злокачественных новообразований некоторые авторы не считают его истинным паранеопластическим дерматозом, что требует дальнейших исследований [37, 38].

Общеизвестно, что кожа принимает активное участие в метаболизме гормонов, и любые изменения гормонального фона влияют на структурные изменения в кожных покровах. Снижение концентрации 17-В-эстрадиола у женщин с возрастом приводит к ухудшению чувствительности тканей к инсулину и формированию инсулинорезистентности. Кроме того, имеются положительные влияния эстрогенов в виде снижения факторов воспаления (С-реактивного белка, TNF-L), торможения апоптоза эпителиальных клеток, снижения уровня эндотелина-1, что способствует развитию менопаузального метаболического синдрома [39]. В исследованиях отечественных и зарубежных коллег нам не встретилось работ, касающихся изучения уровня содержания глюкозы и инсулина у пациентов при себорейном кератозе.

О возникновении и прогрессировании СК на фоне иммуносупрессии, подтвержденной патогистологическими исследованиями иммуноклеточных реакций и процессов ангиогенеза в образцах кожи пациентов, а также нарушений «цитокератинового» профиля и диффреренцировки кератиноцитов, говорится в исследованиях Ю.В. Лебедевой [16]. Иммунногистохимическим методом с использованием моноклональных антител было проведено выявление эндотелия сосудов (CD 34), активированных моноцитов и макрофрагов CD 68, Т- и В-клеток (CD 3, CD 20), цитокератинов 5, 8, $9,11,14,17,18$, антител к маркеру пролиферативной активности Ki-67 и онкопротеину bcl-2. В результате проведенных исследований определена вариабельная пролиферативная активность разных видов СК, показана прямая зависимость между значением индекса пролиферации и показателем экспрессии bcl-2, установлено нарушение диффреренцировки кератиноцитов из-за неполноценного синтеза цитокинов. Автор обнаружил нарушения стромообразования, усиления ангиогенеза, наличие иммунноклеточной реакции разной степени интенсивности, а у пациентов с онкопатологией был выражен полиморфизм клеток многослойного плоского эпителия. В исследованиях D. Broekaert с соавт. и M. Nindl c соавт. [40, 41] выявлено нарушение клеточной диффреренцировки в виде повышенной экспрессии «пролиферативных» цитокератинов 6-го и 16-го типов в кератиноцитах при СК. В зарубежных источниках обращает на себя описание M.E. Vestergaard [42] появления множественных себорейных кератом у пациента с вульгарным псориазом на месте разрешившихся псориатических высыпаний после терапии эфализумабом.

Себорейные кератомы встречаются преимущественно с 30-летнего возраста, когда происходит истончение эпидермиса на 10\%. Эпидермальные кера- 
тиноциты стареют и становятся более устойчивыми к апоптозу. Следовательно, они в большей степени аккумулируют мутации, что увеличивает риск злокачественной трансорормации [37, 43]. S. Nakamura с соавт. [44], исследуя 5 образцов тканей СК, не обнаружили фрагментации ДНК в клетках, тогда как в контрольных образцах здоровой кожи фрагментация ДНК была зафиксирована в зернистом и роговом слое эпидермиса. Продолжительность жизни большинства культивированных клеток СК была на 3 недели дольше в отличие от нормальных кератиноцитов. Данное обстоятельство говорит о сдерживании апоптоза в клетках СК.

Принимая во внимание возможность генетической предрасположенности как основного этиологического фрактора, C. Hafner [29], исследуя как лиц, имеющих множественные себорейные кератомы в 2 поколениях семьи, так и спорадические случаи, обнаружил мутации гена третьего рецептора фрактора роста фрибробластов (FGFR-3), частота которых повышалась с увеличением возраста пациентов и при локализации себорейных кератом в области головы и шеи. Соматические мутации гена FGFR-3 или хромосомные транслокации в регионе рецепторов были идентифицированы при некоторых злокачественных опухолях - множественной миеломе, карциномах урогенитального тракта $[45,46]$. При изучении себорейных кератом аденоидного типа мутации были выявлены в 85\% случаев. Также была замечена прямая корреляция между частотой обнаружения данных мутаций и повышением экспрессии bcl-2 и протеина FGFR-3 в кератиноцитах базального слоя. Сочетание данных мутаций с возрастом и локализацией СК на коже и шее может свидетельствовать о роли длительного воздействия ультрафиолета в патогенезе СК [12]. При других гистологических типах СК - акантотическом и гиперкератотическом - число мутаций не превышало 40\%, по данным A. Logie с соавт. [47]. Автор исследовал всего 4 пациентов с солитарными себорейными кератомами, из них у одного пациента мутации выявлены не были. Наличие такого высокого коэффрициента мутаций гена FGFR-3 более не было выявлено ни при каких других опухолях кожи. При злокачественных новообразованиях - базально-клеточном раке и плоскоклеточной карциноме - мутации гена FGFR-3, по данным зарубежных исследователей, обнаружены не были [48]. На возможность генетического мозаицизма при СK указывает также наблюдение Т. Mabuchi с соавт. [49] у 66-летнего мужчины расположения множественных себорейных кератом по линиям Блашко.

До настоящего времени нет единого представления о состоянии пролиферативной активности клеток при СК. Результаты работ по изучению маркера пролиферации Кі-67, по данным разных авторов, крайне противоречивы [4, 16, 51]. Главным фактором, контролирующим пролиферацию кератиноцитов в себорейных кератомах, считают р27 (Кip1) на основании его выраженной и дифрфузной экспрессии при иммунногистохимическом исследовании, не характерной для других новообразований кожи. Так, А.K. Bruecks c coавт. [14], изучив 10 себорейных кератом акантотического типа и 10 раздраженного типа, в обоих группах отметили низкий индекс пролиферации по степени экспрессии Кі-67 в сочетании с диффузной экспрессией белка р27 и практически отсутствием другого циклин-зависимомого ингибитора киназы - p16. Однако S. Nakamura [44] ведущую роль в патогенезе CK отдает как раз онкогену р16. При иммуногистохимическом исследовании он обнаружил его экспрессию во всех клетках СК, тогда как в норме присутствие р16 характерно только для кератиноцитов зернистого слоя. Кроме того, р16 обнаруживался и в культивированных клетках себорейных кератом. Экспрессия р53 была изучена частично, при отдельных видах СК, и не дает представления о роли онкопротеина в патогенезе заболевания [30, 44, 51].

Повышение экспрессии рецепторов эпидермального фрактора роста (EGF-R) характерно для многих гиперпролиферативных заболеваний, однако не универсально. L.B. Nanney с соавт. [53], изучив экспрессию EGF-R в растущих (оценивалась клеточная пролиферация с использованием 5-бромодеоксиуридина) и покоящихся себорейных кератомах, нитевидных папилломах, вульгарных бородавках и при контагиозном моллюске, отметили увеличение экспрессии только в растущих элементах себорейных кератом и папиллом. Иммуногистохимическим методом не было обнаружено EGF-R при вульгарных бородавках, при контагиозном моллюске интенсивное окрашивание наблюдалось в базальных кератиноцитах и отсутствовало в пораженных вирусом клетках. Таким образом, повышение экспрессии EGF-R коррелировало с пролиферацией лишь при двух разных эпидермальных заболеваниях. Это единичное исследование, проведенное на 5 образцах себорейных кератом, без описания гистологических фрорм, локализации и распространенности высыпаний не дает возможности полноценно судить о роли EGF-R в патогенезе CK.

Нами не было найдено данных об исследовании экспрессии при солитарных себорейных кератомах трансформирующего фрактора роста-L, важного эндогенного медиатора гиперпролиферативных заболеваний кожи.

Многими авторами предпринимались попытки определить роль вируса папилломы человека (ВПЧ) в развитии СК, исходя из данных о клинической и гистологической схожести плоских бородавок, аногенитальных кондилом и себорейных кератом, однако до сих пор вирусная природа заболевания остается спорной [55, 56, 61-63]. Высокий процент обнаружения ДНК ВПЧ в СК регистрируется при локализации их на половых органах. В исследованиях J.C. Tardio с соавт. [57] 70\% генитальных себорейных кератом (40/28) содержали 
ДНК ВПЧ преимущественно 18-го (высокоонкогенного) и 6-го типов, тогда как при экстрагенитальной локализации только в 10\% (20/2) кератом регистрировалась положительная реакция. E.S. Lee c coaвт. [58], исследовав с помощью ПЦР 40 образцов себорейных кератом негенитальной локализации, ни в одном случае не обнаружили наличие ДНК ВПЧ 6/11, 31, 33-го типов. Есть данные об ассоциации СК с ВПЧ рода beta в 70\% случаев [59], а также об отсутствии ДНК вируса при исследовании 50 пациентов с СК, локализующимися на коже лица [15]. A. Gushi с соавт. [60] изучили 104 негенитальных себорейных кератомы на наличие ДНК вируса папилломы человека (ВПЧ), используя молекулярные методы исследования: гибридизацию in situ (ISH), ПЦР, Southern (Саузерн)-блот-гибридизацию и секвенирование вирусной ДНК в ПЦР-амплифицированных фрагментах. Иммуногистохимический метод использовался для детализации вириона (протеин капсулы ВПЧ) в ISHположительных образцах. Были использованы 2 кожных и 8 слизистых типов ВПЧ. При использовании ISH 28,8\% СК содержали ДНК ВПЧ, во всех образцах был обнаружен вирион в ядрах кератиноцитов. При ПЦР 83,7\% образцов содержали ВПЧ 18-го типа, 77,9\% ВПч 6-го типа и 70,2\% - обоих типов. В 20 контрольных образцах была выявлена негативная реакция при ISH, однако в 7 обнаружилась ДНК ВПЧ при секвенировании (ПЦР). Автор предположил, что коинфекция ВПЧ 6-го и 18-го типов играет важную роль в патогенезе СК. Однако автором не указано на наличие у пациентов ассоциированных с СК ВПЧ-обусловленных заболеваний кожи (бородавок, папиллом, аногенитальных кондилом), что делает выявление при СК ВПЧ не совсем достоверным. На данный фракт указывает обнаружение автором ДНК ВПЧ в контрольных образцах.

Вызывает особый интерес обнаруженное Y. Zhang с соавт. [64] при помощи количественной ПЦР уве- личение содержания в клетках себорейных кератом мРНК эндотелина-1, активация которого ведет к повышению пролиферативной активности клеток и увеличению их жизненного цикла. Увеличению продукции эндотелина, в свою очередь, способствует повышение экспрессии фактора некроза опухолей $-1 \mathrm{~L}$ (FNF-1 alpha) и эндотелинпревращающего фермента-L (ECE-1 alpha) в базалоидных клетках при себорейном кератозе [65]. Учитывая данные исследований Y. Takenaka с соавт. [66] о ведущей роли эндотелина, митогена и меланогена в активации меланоцитов при гиперпигментациях, вызванных УФ-облучением и при сенильном лентиго, вызывает интерес изучение его участия в механизмах гиперпигментации при себорейных кератомах. Тем более что в возрасте, когда преимущественно развивается себорейный кератоз, на 15-20\% снижается число ферментативно активных меланоцитов, что приводит к ослаблению защитного барьера кожи, обеспечивающего защиту от негативного воздействия УФ-облучения [37].

Таким образом, разнообразие клинических и гистологических фрорм себорейного кератоза, которое приводит к расхождениям в диагнозе, многочисленность сообщений о злокачественной трансформации СК, о коллизионных опухолях, содержащих СК и злокачественное новообразование, о наличии мутаций и экспрессии онкопротеинов, характерных для злокачественных новообразований кожи, определяет важность дальнейших исследований, включающих в себя изучение процессов пролиферации и меланогенеза при различных типах себорейных кератом, при сочетании с другими опухолями кожи, влияние гиперинсулинемии на клиническую картину заболевания и пролиферативную активность клеток. Это позволит прийти к пониманию патогенеза, усовершенствовать диагностику и тактику дальнейшего ведения пациентов с CK. I

\section{Литература}

1. Skripkin U.K., Mordovzeva V.N. Skin and venereal diseases. The management for doctors. $M$ : Medicina; 1999. [Скрипкин Ю.К., Мордовцева В.Н. Кожные и венерические болезни. Руководство для врачей. М: Медицина; 1999.]

2. Mordovzeva V.N., Zvetkova G.N., Skin pathology. M: Medicina; 1993. [Мордовцева B.H., Цветкова Г.М. Патология кожи. М.: Медицина; 1993.]

3. Habif T.P. Skin disease: diagnosis and treatment. Second edition M: MEDpress; 2006 [Хэбиф Т.П. Кожные болезни: Диагностика и лечение; Пер. с англ.; Под общей ред. акад. РАМН, проф. А.А. Кубановой. М.: МЕДпресс-информ; 2006.]
4. Hafner C., Hartmann A., van Oers J.M., Stoehr R., Zwarthoff E.C., Hofstaedter F., Landthaler M. FGFR3 mutations in seborrheic keratoses are already present in flat lesions and associated with age and localization /Mod Pathol. 2007 Aug; 20 (8): 895-903.

5. Gulias-Cañizo R., Aranda-Rábago J., Rodríguez-Reyes A.A. Seborrheic keratosis of conjunctiva: a case report.Arch Soc Esp Oftalmol. 2006 Apr; 81 (4): 217-9.

6. Kim J.H., Bae H.W., Lee K.K., Kim T.I., Kim E.K. Seborrheic keratosis of the conjunctiva: a case report. Korean J Ophthalmol. 2009 Dec; 23 (4): 306-8.
7. Kwon O.S., Hwang E.J., Bae J.H., Park H.E., Lee J.C., Youn J.I., et al. Seborrheic keratosis in the Korean males: Causative role of sunlight. Photodermatol Photoimmunol Photomed. 2003; 19 (2): 73-80.

8. Noiles K., Vender R. Are all seborrheic keratoses benign? Review of the typical lesion and its variants. J Cutan Med Surg. 2008 Sep-0ct; 12 (5): 203-10.

9. Zvetkova G.M., Mordovzeva V.V., Vavilov A.M., Mordovzev V. V. Pathomorfology of skin diseases. M: Medicina; 2003. [Цветкова Г.М., Мордовцева В.В., Вавилов А.М., Мордовцев В.Н. Патоморфология болезней кожи. М.: Медицина; 2003.] 
10. Yoshimi N., Imai Y., Kakuno A., Tsubura A., Yamanishi K., Kurokawa I. Epithelial keratin and filaggrin expression in seborrheic keratosis: evaluation based on histopathological classification. International J Dermatol. 2013 Jun 20: 34-36.

11. Requena L., Kutzner H. Seborrheic keratosis with pseudorosettes and adamantinoid seborrheic keratosis: two new histopathologic variants. J Cutan Pathol. 2006 Sep; 33 Suppl 2: 42-5.

12. Christian Hafner, Johanna M.M. van Oers, Arndt Hartmann, Michael Landthaler, High Frequency of FGFR3 Mutations in Adenoid Seborrheic Keratoses/ Journal of Investigative Dermatology (2006) 126, 2404-2407.

13. Mekni A., Bouraoui S., Kchir N., Kort R., Bellil K.E. May A. Malignancy arising in seborrheic keratosis: two cases report. Tunis Med. 2003 Oct; 81 (10): 835—8.

14. Bruecks A.K., Kalia S., Trotter M.J. Overexpression of p27KIP1 in seborrheic keratosis. J Cutaneous Medicine and Surgery. 2007 Sep-Oct; $11(5): 174-8$

15. Meibodi N.T., Nahidi Y., Meshkat Z., Esmaili H., Gharib M., Gholoobi A. N. Evidence of Human Papillomaviruses in Non-genital Seborrheic Keratosis. Indian J Dermatol. 2013 Jul; 58 (4): 326

16. Lebedeva U.V., Davidov A.B. Clinical assessment of prevalence of seborrheic keratosis face skin and a neck among oncological patients. Stomatologia 2009; (5): 45-48. [Лебедева Ю.В., Давыдов А.Б. Клиническая оценка распространенности себорейного кератоза кожи лица и шеи среди онкологических больных. Стоматология 2009; (5): 45-48.]

17. Groesser L., Herschberger E., Landthaler M. Hafner C. FGFR3, PIK3CA and RAS mutations in benign lichenoid keratosis. $\mathrm{Br} \mathrm{J}$ Dermatol. 2012 Apr; 166 (4): 784—8.

18. Jee H., Lee N.R., Ahn S.K. Case of seborrheic keratosis with underlying basal cell carcinoma suggesting a collision tumor. J Dermatol. 2013 Oct; 40 (10): 837—9.

19. Laing M.E., O'Keane C., Murphy G.M. Basal cell carcinoma arising in a seborrhoeic keratosis. Clin Exp Dermatol. 2009 Oct; 34 (7): e371-2

20. Lee J.Y., Lin M.H. Pigmented malignant hidroacanthoma simplex mimicking irritated seborrheic keratosis. J Cutan Pathol. 2006 Oct; 33 (10): $705-8$.

21. Akasaka T., Kon S. Two cases of basal cell carcinoma arising in seborrheic keratosis. J Dermatol. 1997 May; 24 (5): 322-7.

22. Izikson L., Sober A.J., Mihm M.C. Jr., Zembowicz $A$. Prevalence of melanoma clinically resembling seborrheic keratosis: analysis of 9204 cases. Arch Dermatol. 2002 Dec; 138 (12): 1562-6.

23. Vun Y., De'Ambrosis B., Spelman L., Muir J.B., Yong-Gee S., Wagner G., Lun K. Seborrhoeic keratosis and malignancy: collision tumour or malignant transformation? Australas J Dermatol. 2006 May; 47 (2): 106_-8.
24. Rajabi P., Adibi N., Nematollahi P., Heidarpour M., Eftekhari M., Siadat A.H. Bowenoid transformation in seborrheic keratosis: A retrospective analysis of 429 patients. J Res Med Sci. 2012 Mar; 17 (3): 217-21.

25. Thomas I., Kihiczak N.I., Rothenberg J., Ahmed S., Schwartz R.A. Melanoma within the seborrheic keratosis. Dermatol Surg. 2004 Apr; 30 (4 Pt 1): 559-61.

26. Terada T., Kamo M, Baba Y., Sugiura M. Microinvasive squamous cell carcinoma arising within seborrheic keratosis. Cutis. 2012 0ct; 90 (4): 176 - 8 .

27. Ishida M., Ohsato N., Okabe H. Basal cell carcinoma arising within a seborrheic keratosis with respect to immunohistochemical characteristics. Oncol Lett. 2011 Jul; 2 (4): 625—627.

28. Lim C. Seborrhoeic keratoses with associated lesions: a retrospective analysis of 85 Iesions. Australas J Dermatol. 2006 May; 47 (2): 109-13

29. Hafner C., Vogt T., Landthaler M., Müsebeck J. Somatic FGFR3 and PIK3CA mutations are present in familial seborrhoeic keratoses. $\mathrm{Br} \mathrm{J}$ Dermatol. 2008 Jul; 159 (1): 214 —7.

30. Ko C.J., Shintaku P., Binder S.W. Comparison of benign keratoses using p53, bcl-1, and bcl2. J Cutan Pathol. 2005 May; 32 (5): 356-9.

31. Wrone D.A., Yoo S., Chipps L.K., Moy R.L. The expression of p63 in actinic keratoses, seborrheic keratosis, and cutaneous squamous cell carcinomas. Dermatol Surg. 2004 0ct; 30 (10): 1299-302.

32. Heaphy M.R. Jr., Millns J.L., Schroeter A.L. The sign of Leser-Trelat in a case of adenocarcinoma of the lung. J Am Acad Dermatol. 2000; 43: 386-390. doi: 10.1016/S0190-9622 (00)70301-X.

33. Ellis D.L., Kafka S.P., Chow J.C. Melanoma, growth factors, acanthosis nigricans, the sign of Leser-Trelat, and multiple acrochordons. A possible role for alpha-transforming growth factor in cutaneous paraneoplastic syndromes. N Engl J Med. 1987; 317 (25): 1582-1587.

34. Ponti G., Luppi G., Losi L., Giannetti A., Seidenari S. Leser-Tre'lat syndrome in patients affected by six multiple metachronous primitive cancers. J Hematology Oncol. 2010 Jan $11 ; 3: 2$.

35. Saraiya A., Al-Shoha A., Brodell R.T. Hyperinsulinemia associated with acanthosis nigricans, finger pebbles, acrochordons, and the sign of Leser-Trélat. Endocr Pract. 2013 MayJun; 19 (3): 522-5.

36. Blomberg M., Jeppesen E.M., Skovby F., Benfeldt E. FGFR3 mutations and the skin: report of a patient with a FGFR3 gene mutation, acanthosis nigricans, hypochondroplasia and hyperinsulinemia and review of the literature. Dermatology. 2010; 220 (4): 297-30.

37. Wolff K.L., Goldsmith A.L. et al. Fitzpatrick s Dermatology in General Medicine, seventh edition, McGraw-Hill Medical., 2013: 1635-36.

38. Wieland C.N., Kumar N. Sign of Leser-Trélat. Int J Dermatol. 2008 Jun; 47 (6): 643—4.
39. Smetnik V.I., Kulakov V.I. The management on a klimakteriya. M: Medical information agency; 2001. [Сметник В.П., Кулакова В.И. Руководство по климактерию. М: Медицинское инсрормационное агентство. 2001.]

40. Broekaert D., Leigh I.M., Lane E.B., Van Muijen G.N., Ramaekers F.C., De Bersaques J. An immunohistochemical and histochemical study of cytokeratin, involucrin and transglutaminase in seborrhoeic keratosis. Arch Dermatol Res. 1993; 285 (8): 482—90.

41. Nindl M., Nakagawa H., Furue M., Ishibashi Y Simple epithelial cytokeratin-expression in seborrheic keratosis J Cutan Pathol. 1992 Oct; 19 (5): 415-22.

42. Vestergaard M.E., Kossard S., Murrell D.F. Seborrhoeic keratoses appearing in sites of previous psoriasis plaques during treatment with efalizumab. Clin Experiment. Dermatol. 2009 Dec; 34 (8): e564—6.

43. Hida Y., Kubo Y., Arase S. Activation of fibroblast growth factor receptor 3 and oncogeneinduced senescence in skin tumours. $\mathrm{Br} \mathrm{J}$ Dermatol. 2009 Jun; 160 (6): 1258-63.

44. Nakamura S., Nishioka K. Enhanced expression of p16 in seborrhoeic keratosis; a lesion of accumulated senescent epidermal cells in G1 arrest. Br J Dermatol. 2003 Sep; 149 (3): 560-5.

45. Hafner C., Toll A., Fernández-Casado A., Earl J., et al. Multiple oncogenic mutations and clonal relationship in spatially distinct benign human epidermal tumors. Proceedings Natl Acad Sci U. S. A. 2010 Nov 30; 107 (48): 20780-5.

46. Hafner C., Kamenisch Y., Landthaler M., Berneburg M. Distinct profile of the mitochondrial DNA common deletion in benign skin lesions. Experimental Dermatol. 2011 Feb; 20 (2): 151—3.

47. Logie A., Dunois-Larde C., Rosty C. et al. Activating mutations of the tyrosine kinase receptor FGFR3 are associated with benign skin tumors in mice and humans. Hum Mol. Genet 14: 1153 - 1160

48. Karoui M., Zimmermann U., Degott C. et al. No evidence of somatic FGFR3 mutation in various types of carcinoma. Onkogene 2001 № 20: 5059-61.

49. Mabuchi T., Akasaka E., Kondoh A., Umezawa Y., Matsuyama T., Ozawa A. Seborrheic keratosis that follows Blaschko's lines. Dermatol. 2008 May; 35 (5): 301-3.

50. Ceylan C., Alper S, Kilinç I. Leser-Trelat sign. Int J Dermatol. 2002 0ct; 41 (10): 687-8.

51. Kamiya M., Takeuchi Y., Katho M., Yokoo H., Sasaki A., Nakazato Y. Expression of p73 in normal skin and proliferative skin lesions. Pathol Int. 2004 Dec; 54 (12): 890—5.

52. Shamsadini S., Wadji M.B., Shamsadini A. Surrounding ipsilateral eruptive seborrheic keratosis as a warning sign ofintraductal breast carcinoma and Paget's disease (Leser Trelat sign). Dermatol Online J. 2006 Oct 31; 12 (6): 27.

53. Nanney L.B., Ellis D.L., Levine J., King L.E. Epidermal growth factor receptors in idiopathic and virally induced skin diseases. Am J Pathol. 1992 Apr; 140 (4): 915—25. 
54. Puizina-Ivić N., Sapunar D., Marasović D. Mirić $\mathrm{L}$. An overview of $\mathrm{BCl}-2$ expression in histopathological variants of basal cell carcinoma, squamous cell carcinoma, actinic keratosis and seborrheic keratosis. Collegium Antropol. 2008 Oct; 32.

55. Akgül B., Cooke J.C., Storey A. HPV-associated skin disease. J Pathol. 2006 Jan; 208 (2): 165-75.

56. Forslund O., LyH., Reid C., Higgins G. A broad spectrum of human papillomavirus types is present in the skin of Australian patients with non-melanoma skin cancers and solar keratosis Br J Dermatol. $2003 \mathrm{Jul} ; 149$ (1): 64—73.

57. Tardío J.C., Bancalari E., Moreno A., MartínFragueiro L.M. Genital seborrheic keratoses are human papillomavirus-related lesions. A linear array genotyping test study. 2012 Jun; 120 (6): 477-83.

58. Lee E.S., Whang M.R., Kang W.H. Absence of human papillomavirus DNA in nongenital seborrheic keratosis. J Korean Med Sci. 2001 Oct; 16 (5): 619-22.
59. Kladova A.U. Association of the epitelian tumors of skin with Human papilloma viruses. Doctor 2011; (13): 5-7. [Кладова А.Ю. Ассоциация эпителиальных опухолей кожи с вирусами папилломы человека. Доктор 2011; (13): 5-7.]

60. Gushi A., Kanekura T., Kanzaki T., Eizuru Y. Detection and sequences of human papillomavirus DNA in nongenital seborrhoeic keratosis of immunopotent individuals. J Dermatol Sci. 2003 Apr; 31 (2): 143—9.

61. Meyer T., Arndt R., Christophers E., Nindl I. \& Stockfleth E. (2001). Importance of human papillomaviruses for the development of skin cancer. Cancer Detect Prev 25, 533-547.

62. Pfister H. \& Ter Schegget J. Role of HPV in cutaneous premalignant and malignant tumors. Clin Dermatol 1997; 15: 335-347.

63. Zhu W.Y., Leonardi C., Penneys N.S. Detection of human papillomavirus DNA in seborrheic keratosis by polymerase chain reaction J Dermatol Sci. 1992 Nov; 4 (3): 166—71.
64. Zhang Y., Tang L., Su M., Eisen D., Zloty D., Warshawski L., Zhou Y. Expression of endothelins and their receptors in nonmelanoma skin cancers. J Cutan Med Surg. 2006 Nov-Dec; 10 (6): 269-76.

65. Manaka L., Kadono S., Kawashima M., Kobayashi T., Imokawa G.The mechanism of hyperpigmentation in seborrhoeic keratosis involves the high expression of endothelinconverting enzyme-1alpha and TNF-alpha, which stimulate secretion of endothelin $1 . \mathrm{Br} \mathrm{J}$ Dermatol. 2001 Dec; 145 (6): 895—903.

66. Takenaka Y., Hoshino Y., Nakajima H., Hayashi N., Kawashima M., Imokawa G. Paracrine cytokine mechanisms underlying the hyperpigmentation of seborrheic keratosis in covered skin areas. J Dermatol. $2013 \mathrm{Jul} ; 40$ (7): 533-42.

об авторах:

А.К. Александрова — к.м.н., докторант кафедры патологической анатомии им. акад. А. И. Струкова ГБоУ ВПо Первый МГмУ им. И.М. Сеченова Минздрава России, Москва

В.А. Смольянникова - д.м.н., профессор кафедры патологической анатомии им. акад. А. И. Струкова ГБоу ВПо Первый МГМУ им. И.М. Сеченова Минздрава России, Москва

\section{Конфликт интересов}

Авторы заявляют об отсутствии потенциального конфрликта интересов, требующего раскрытия в данной статье 